\title{
Effectiveness of marketing expenditures: A brand level case study
}

Received (in revised form): 22nd July, 2007

\section{Mehir Kumar Baidya}

is a PhD student in Marketing at Indian Institute of Technology, Kharagpur-721302, West Bengal, India. His educational background is a BE (Chemical) followed by an MBA (Marketing) from Pune University. He also teaches at Indian Institute of Social Welfare and Business Management, Kolkata, India.

\section{Partha Basu}

is Professor of Economics, Department of Humanities and Social Sciences, Indian Institute of Technology, Kharagpur-721302, West Bengal, India. He has an MA and PhD in Economics from Calcutta University. His areas of specialisation are Statistics and Econometrics.

Keywords marketing expenditures, marketing efforts, effectiveness, sales, CSI and ROI

\begin{abstract}
Marketing efforts often have not been subjected to the same rigorous analysis and evaluation that is routinely applied to the other areas within a firm. There is an increasing concern that these efforts should be required to undergo similar analysis and control. The present work is carried out with the aim of studying the impact of individual marketing efforts (advertising, salesforce, promotion, distribution and price) on sales and overall customer satisfaction for a brand (Navratna) by taking into consideration both the financial and nonfinancial aspects of the measurement. The returnon-investment (ROI) has been calculated for each effort on the basis of sales and adjusted for the respective customer satisfaction indices (CSI). The results have been compared to get an idea about the relative effectiveness of each marketing effort on sales, CSI and ROI. The findings suggest that all the marketing efforts have significant positive impact on sales except price. Moreover, all the marketing efforts have significant positive effects on overall customer satisfaction for the brand. Furthermore, among all the marketing efforts the adjusted ROI is the highest for salesforce. These results will assist the managers in allocating the resources to different marketing efforts in a better manner, so as to improve the effectiveness of marketing expenditures.

Journal of Targeting, Measurement and Analysis for Marketing (2008) 16, 181-188. doi:10.1057/jt.2008.12; published online 30 June 2008
\end{abstract}

\section{INTRODUCTION}

Corporations are engaged as corporate cost cutters to maximise the shareholders' return. Marketing is at the top of the list because this is the area where rigorous financial evaluations have not been used extensively to justify the expenditures within a firm. Manufacturing costs have been reduced from 50 per cent to 30 per cent, and general management costs have

Correspondence: Mehir Kumar Baidya, Department of MBA (E), Indian Institute of Social Welfare and Business Management, Management House, College Square (West), Kolkata-700073, India. Tel: 91-9474505464;

E-mail: meetmehir22@yahoo.co.in also declined as a proportion of the total corporate costs from 30 per cent to 20 per cent, but in contrast to manufacturing and general management costs, marketing costs have increased significantly from only 20 per cent of the total corporate costs 50 years ago to 50 per cent today. ${ }^{1}$

In spite of the huge marketing expenditures, managers frequently do not have concrete measures or knowledge of what is obtained in return from a significant investment in marketing. Moreover, many have doubted that definite quantitative measurements of marketing effectiveness could ever be made. Without 
measurement of return-on-investment (ROI), weak and ineffectual programmes continue year after year, consuming large sums of money.

To assess the effectiveness of marketing expenditures, both financial and nonfinancial indicators are needed. The financial indicators are sales, profits, ROI, etc. The nonfinancial indicators are customer satisfaction index (CSI), awareness level of customers, purchase intentions, etc. It is necessary to move beyond sole reliance on financial indicators for measuring the effectiveness of marketing programmes. For instance, in the case of consumer goods, where repeat buying is an important aspect, measuring the satisfaction level of customers (nonfinancial indicator) will be helpful. Moreover, a manager clearly needs a combination of both the financial and nonfinancial indicators to get an idea about the effectiveness of individual marketing efforts.

\section{PURPOSE}

The purpose of this paper is twofold. First, the relationship between marketing efforts (advertising, salesforce, sales promotion, distribution and price) and sales will be examined. Further, the relationship between customers' emotional reactions towards each marketing effort and overall customer satisfaction will be investigated. Secondly, the CSI and adjusted ROI for each effort will be calculated. The results will be used to compare the effectiveness of individual marketing efforts for the brand.

The structure of this paper is as follows: first, the previous related studies have been discussed very briefly. The objectives, models, hypotheses and methodology have been presented in the next section. These are followed by the results and discussion, conclusion and managerial implications, limitations and directions for further research.

\section{REVIEW OF LITERATURE}

Studies on Marketing Efforts: Studies related to individual marketing efforts have been discussed in turn.

Effects of advertising: There have been a number of studies relating sales with advertising. Stone and Duffy ${ }^{2}$ and Basu and Batra ${ }^{3}$ used the judgmental and mathematical (ADSPLIT) models to frame the relationship between sales and advertising expenditures. Both studies used response function to allocate marketing budget to advertising as well as to different brands.

Effects of sales promotion: Bawa and Shoemaker ${ }^{4}$ performed a study to identify the influence of sales promotion activities on customers' brand choice behaviour. The authors found that sales promotion activities have short-term and longterm positive effects on the brand choice behaviour of customers. In the same direction, Jones ${ }^{5}$ made an attempt to examine the shortterm and long-term impact of sales promotion activities on sales by a multivariate technique. Regression model estimation indicates that the short-term effect is more prominent than the long-term.

Effects of distribution: With the advent of lean production, total quality management and just-intime deliveries, organisations have been building closer working relationships with a reduced number of suppliers. ${ }^{6}$ Ogbonna and Wilkinson ${ }^{7}$ commissioned a survey to identify the nature of the relationships between food manufacturers and retailers. The authors claimed that the relationships are more complex than the general notion of 'partnerships'.

Effects of salesforce: Traditional selling approaches have changed in the context of competition, and in the future, too, the role of salesforce will change. ${ }^{8} \mathrm{~A}$ financial model can be applied for evaluating the observed expenditures versus expected returns to measure the effectiveness (in terms of sales) of salesforce effort. ${ }^{9}$

Effects of price: Eskin ${ }^{10}$ has performed a test market experiment to identify the impact of price with advertising on sales for a new product, and used three price levels (base, +0.10 and +0.20 ) and two advertising levels (low and high). The author found that the effect of a low price on attracting buyers depends on the level of advertising. The high advertising plan produces sales 50 per cent above the low plan at the base price. At the middle price it was 34 per cent, and at the highest price with the high advertising level it was only 11 per cent. 
Customer Satisfaction Studies: Anderson et al. ${ }^{11}$ analysed a database matching the CSI with ROI, and the productivity of each company covered by the Swedish Customer Satisfaction Barometer (SCSB) from 1989 to 1992. Regression model estimation indicates that the coefficient for the direct relationship between the customer satisfaction and ROI is positive and significant. Similarly, Ittner and Larcker ${ }^{12}$ extend this study by using stock price as a dependent variable and CSI as an independent variable. The authors found that the estimated regression coefficient is 7.36. This shows that customer satisfaction has a positive impact on shareholder value.

\section{OBJECTIVES}

The following three objectives have been identified:

1. To study the impact on sales of individual marketing efforts such as advertising, sales promotion, salesforce, distribution and price, as independent variables.

2. To investigate the relationship between overall customer satisfaction level as a categorical dependent variable, and the customer's emotional reactions towards each marketing effort, acting as metric independent variables.

3. To obtain adjusted ROI in each marketing effort providing due adjustment for the respective customer satisfaction indices.

\section{EMPIRICAL MODEL}

In this study, three models have been considered and are presented below:

\section{Model for objective 1}

A double $\log$ function (Equation (1)) has been considered for Objective 1. This form has been chosen because there is some support for a convex-concave or S-shaped response function to each marketing effort. Moreover, many empirical studies support the diminishing marginal return to each marketing effort. ${ }^{3}$

$$
Y_{t}=e^{\beta_{0}+u_{t}} X_{1 t}^{\beta_{1}} X_{2 t}^{\beta_{2}} X_{3 t}^{\beta_{3}} X_{4 t}^{\beta_{4}} X_{5 t}^{\beta_{5}}, \quad \text { for } t=1,2, \ldots, T
$$

Notation: $Y_{t}=$ Volume of sales in terms of rupees for period $t ; X_{1 t}=$ Advertising expenditures in terms of rupees for period $t ; X_{2 t}=$ Salesforce expenditures in terms of rupees for period $t$; $X_{3 t}=$ Sales promotion expenditures in terms of rupees for period $t ; X_{4 t}=$ Distributors' commission paid in terms of rupees for period $t ; X_{5 t}=$ Price of product in terms of rupees for period $t$; and $u_{t}=$ Random disturbance term.

\section{Model for objective 2}

A logistic regression model (Equation (2)) with maximum likelihood estimation algorithm has been used for Objective 2. This form has been taken because the response variable is collected in binary form. At the same time, the present study is based on an assumption that marketing efforts may exhibit diminishing marginal returns in terms of probability of the customer being satisfied overall. ${ }^{11}$ That is, the overall customer satisfaction function is nonlinear with respect to individual marketing efforts.

$$
\ln \left(\frac{p}{1-p}\right)=\lambda_{1} Q_{1}+\lambda_{2} Q_{2}+\lambda_{3} Q_{3}+\lambda_{4} Q_{4}+\varepsilon
$$

Notation: $p / 1-p$ odds ratio and $0 \leqslant p \leqslant 1$; $Q_{1}=$ Score of customer's emotional reactions to advertisement; $Q_{2}=$ Score of customer's emotional reactions to product attributes; $Q_{3}=$ Score of customer's emotional reactions to availability of the product; $Q_{4}=$ Score of customer's emotional reactions to the price of the product; and $\varepsilon=$ Random disturbance term.

\section{Model for objective 3}

The model (Equation (3)) for Objective 3 is postulated below. The idea of this model has been taken from Sheth and Sisodia's paper. ${ }^{1}$

$$
R O I_{i}=\beta_{i} \star(C S I)_{i}
$$

Notation: $R O I_{i}=$ Return-on-investment in the $i$ th marketing effort; $\beta_{i}=$ Incremental sales for the $i$ th marketing effort; and $(C S I)_{i}=$ Customer satisfaction index for the $i$ th marketing effort. 


\section{HYPOTHESES}

Research hypotheses emanate from three possible sources: theory, empirical observation and experience. ${ }^{13}$ Taking these sources into consideration, Equation (1) will be used to test the null hypothesis of no influence of each marketing effort on sales against the research hypothesis of positive/negative effect. And by Equation (2), the null hypothesis of zero influence of the customer's emotional reactions towards each marketing effort on overall customer satisfaction will be tested against the research hypothesis of positive effect.

\section{METHODOLOGY}

Research approach: In this study, both sample survey and statistical approaches have been applied to collect data and establish the relationships between variables of interest.

Sources of data: Both secondary (documents and records of the firm) and primary (a sample of customers in this case) data sources have been used in this work.

Research instrument: The questionnaire has five parts. The first part has 13 statements, which measure the customer's emotional reactions towards advertisements. The second part contains eight statements, which measure the customer's emotional reactions towards the availability of the product. The third part has 12 statements, which measure the customer's emotional reactions towards the product quality. The fourth part consists of 11 statements, which measure the customer's emotional reactions towards the price. All the statements of these four parts have been framed on a five-point Likert scale ranging from 'strongly agree' to 'strongly disagree'. The last part has a single statement regarding the customer's overall satisfaction with the brand and is framed on a binary (yes/no) response format. Reliability and validity of this instrument have been tested and the results are shown in Tables 1 and 2.

Coverage: This present work relates to the whole of West Bengal, a leading eastern state in India, where 11 firms are operating in the hair care products sector. One firm (Emami) was selected at random for this case study. The brand
Table 1: Measures of reliability of each sub-scale of CSS

\begin{tabular}{ll}
\hline Sub-scale & Alpha \\
\hline Advertising items & 0.72 \\
Product items & 0.71 \\
Distribution items & 0.60 \\
Price items & 0.57 \\
\hline
\end{tabular}

(Navratna) of this firm was available in all the major towns in this state at the time of this study.

Sampling of customers: There are 19 districts and 39 towns in West Bengal. Out of 39 towns, 18 have a population of more than one lakh each. The point to be noted is that the firm's marketing efforts have been literally concentrated on those 18 towns. In the first stage of sampling, five towns were selected from 18 at random. In the second stage of sampling, a sample of 30 households was chosen from each selected town. Finally, a sample of total 150 households was selected to represent the state of West Bengal as a whole.

Method of interview: Personal interviews were done by the researcher to collect primary data from the respondents (homemakers in this case).

\section{RESULTS AND DISCUSSION}

To estimate the relationship between sales and individual marketing efforts a regression analysis was performed and results are shown in Table 3. The estimated regression equation is presented below:

$$
\begin{aligned}
\ln (\text { Sales })= & 4.300+0.375 \ln (\text { Advertising }) \\
& +1.200 \ln (\text { Sales force }) \\
& +0.950 \ln (\text { Promotion }) \\
& +0.235 \ln (\text { Distribution }) \\
& -0.500 \ln (\text { Price })
\end{aligned}
$$

The interpretation of this equation is that all the marketing efforts except price have positive effects on sales. The equation also suggests that a 1 per cent increase in these efforts would lead to an increase/decrease in sales for this brand. For instance, the sample elasticity with respect to 
Table 2: Results of factor analysis

\begin{tabular}{|c|c|c|c|}
\hline Items & Factor 1 & Factor 2 & Communality \\
\hline \multicolumn{4}{|c|}{ Advertising sub-scale: } \\
\hline $\mathrm{X} 1$ & 0.71658 & -0.3154 & 0.61296 \\
\hline $\mathrm{X} 2$ & 0.805664 & 0.295218 & 0.73625 \\
\hline X3 & 0.827685 & -0.325312 & 0.79089 \\
\hline $\mathrm{X} 4$ & 0.837947 & -0.209868 & 0.7462 \\
\hline $\mathrm{X} 5$ & 0.783610 & 0.297230 & 0.70239 \\
\hline $\mathrm{X} 6$ & 0.512052 & 0.167504 & 0.29025 \\
\hline $\mathrm{X} 7$ & 0.236216 & 0.776722 & 0.6591 \\
\hline $\mathrm{X} 8$ & 0.562977 & -0.213224 & 0.36241 \\
\hline X9 & 0.614531 & -0.186835 & 0.41256 \\
\hline $\mathrm{X} 10$ & 0.221278 & 0.773190 & 0.64679 \\
\hline $\mathrm{X} 11$ & -0.22366 & 0.764222 & 0.63406 \\
\hline $\mathrm{X} 12$ & 0.73810 & 0.272079 & 0.61882 \\
\hline $\mathrm{X} 13$ & -0.740735 & -0.251450 & 0.61192 \\
\hline Variance & $5.368898(41 \%)$ & $2.455688(18 \%)$ & 7.82459 \\
\hline \multicolumn{4}{|c|}{ Distribution sub-scale: } \\
\hline $\mathrm{X} 1$ & 0.270766 & -0.792357 & 0.701144 \\
\hline $\mathrm{X} 2$ & 0.874175 & 0.216700 & 0.811141 \\
\hline X3 & 0.829744 & 0.252092 & 0.752025 \\
\hline $\mathrm{X} 4$ & 0.712586 & 0.241053 & 0.565885 \\
\hline X5 & 0.778194 & -0.326394 & 0.712119 \\
\hline $\mathrm{X} 6$ & -0.102876 & 0.768531 & 0.601223 \\
\hline $\mathrm{X} 7$ & 0.750397 & -0.313443 & 0.661342 \\
\hline $\mathrm{X} 8$ & 0.850669 & 0.088959 & 0.731551 \\
\hline Variance & $3.936653(49 \%)$ & $1.599779(19 \%)$ & 5.536431 \\
\hline \multicolumn{4}{|c|}{ Product sub-scale: } \\
\hline $\mathrm{X} 1$ & 0.817737 & -0.275569 & 0.744632 \\
\hline $\mathrm{X} 2$ & 0.709213 & 0.345487 & 0.622344 \\
\hline $\mathrm{X3}$ & -0.719380 & 0.339280 & 0.632619 \\
\hline $\mathrm{X} 4$ & -0.860606 & 0.239280 & 0.797898 \\
\hline X5 & 0.304124 & 0.735707 & 0.633756 \\
\hline $\mathrm{X} 6$ & 0.328381 & 0.716606 & 0.621358 \\
\hline $\mathrm{X} 7$ & 0.806219 & 0.342049 & 0.766987 \\
\hline $\mathrm{X} 8$ & 0.802435 & 0.309469 & 0.739673 \\
\hline X9 & 0.747691 & -0.262780 & 0.628095 \\
\hline $\mathrm{X} 10$ & 0.779959 & 0.272056 & 0.682351 \\
\hline $\mathrm{X} 11$ & 0.624025 & 0.252697 & 0.453263 \\
\hline $\mathrm{X} 12$ & 0.300769 & 0.684878 & 0.55952 \\
\hline Variance & $5.571291(46 \%)$ & $2.311204(19 \%)$ & 7.882495 \\
\hline \multicolumn{4}{|c|}{ Price sub-scale: } \\
\hline $\mathrm{X} 1$ & -0.215790 & 0.889927 & 0.838535 \\
\hline $\mathrm{X} 2$ & -0.143296 & 0.759804 & 0.597836 \\
\hline $\mathrm{X3}$ & 0.869392 & 0.331719 & 0.86588 \\
\hline X4 & 0.725878 & 0.248752 & 0.588776 \\
\hline $\mathrm{X} 5$ & -0.724038 & 0.226418 & 0.575496 \\
\hline $\mathrm{X} 6$ & 0.852668 & -0.213794 & 0.772751 \\
\hline $\mathrm{X} 7$ & 0.706488 & 0.310055 & 0.595259 \\
\hline$x 8$ & 0.821921 & 0.231384 & 0.729093 \\
\hline X9 & -0.763441 & 0.254217 & 0.647468 \\
\hline $\mathrm{X} 10$ & -0.627026 & 0.394240 & 0.548587 \\
\hline $\mathrm{X} 11$ & 0.832547 & 0.223375 & 0.743031 \\
\hline Variance & $5.444932(49 \%)$ & $2.057781(19 \%)$ & 7.502713 \\
\hline
\end{tabular}

advertising is 0.375 . This means a 1 per cent increase in advertising would lead to an increase in sales by 0.375 per cent over the study period. Furthermore, this figure indicates that the volume of sales is moderately elastic with respect to advertising effort for this brand. Results also reveal that the partial coefficient of determination $\left(r^{2}\right)$ is highest for price. That is, price has the 
Table 3: Response of sales to marketing efforts of Navratna

\begin{tabular}{|c|c|c|c|c|c|}
\hline \multicolumn{6}{|c|}{$\begin{array}{l}\text { The regression equation: } \\
\ln Y=4.3+0.375 \ln X_{1}+1.200 \ln X_{2}+0.950 \ln X_{3}+0.235 \ln X_{4}-0.500 \ln X_{5}\end{array}$} \\
\hline Predictor & Elasticity & SE & $t$-value & $p$-value & Partial $r^{2 a}$ \\
\hline Advertising & 0.375 & 0.140 & $2.59^{* \star}$ & 0.0095 & 0.544 \\
\hline Salesforce & 1.200 & 0.338 & $3.55^{\star \star}$ & 0.0005 & 0.764 \\
\hline Promotion & 0.950 & 0.370 & $2.56^{\star \star}$ & 0.0095 & 0.423 \\
\hline Distribution & 0.235 & 0.103 & $2.56^{\star \star}$ & 0.0090 & 0.401 \\
\hline Price & -0.500 & 0.067 & $-7.46^{\star}$ & $<0.0000$ & 0.876 \\
\hline
\end{tabular}

Notes: *Significant at 0.001 per cent level (one-tailed), ${ }^{*}$ at 1 per cent level (one-tailed). $X_{1}-$ Advertising expenditures, $X_{2}-$ Salesforce expenditures, $X_{3}$ - Sales promotion expenditures, $X_{4}$ - Distributors' commission, $X_{5}-$ Price, $Y-$ Volume of sales, aEach coefficient below represents in a unit-free form the partial effect of marketing efforts on sales, in both the cases abstracting from the influence of other variables.

Table 4: Validation statistics of regression equation for Navratna

\begin{tabular}{llllll}
\hline Brand & $\boldsymbol{R}^{\mathbf{2}}$ & $\boldsymbol{F}$-value & $\boldsymbol{p}$-value & J-B & D-W \\
\hline Navratna & 0.97 & $198.50^{\star}$ & $<0.000$ & 3.2 & 2.10 \\
\hline
\end{tabular}

Notes: *Significant at 0.001 per cent level, J-B=Jarque-Bera Statistic, D-W=Durbin-Watson Statistic.

greatest impact on sales followed by salesforce, advertising, sales promotion and distribution.

The results of the validation statistics of the regression equation are given in Table 4 . The high value of $R^{2}$ indicates that the sales as a double-log function of individual marketing efforts provide a good fit to the observed data for the brand. Since the value of the JB-statistic is less than the table value, it can be concluded that the error terms are normally distributed in this case. Further, the DW-statistic is not significant, which would lead to the conclusion that the error terms are not serially correlated in the sample data.

To test whether the estimated elasticities of sales with respect to the individual marketing efforts are significantly different from zero, the following hypothesis is formulated in the context of Equation (1):

$\mathbf{H}_{1}$ : The estimated elasticity of sales with respect to each marketing effort is zero.

That is, in mathematical form, $\mathrm{H}_{0}: \beta_{i}=0$ against $\mathrm{H}_{\mathrm{a}}: \beta_{i}>0$ or $\beta_{i}<0$.

The findings (Table 3 ) of the tests of the hypothesis suggest that the coefficients of individual marketing efforts such as advertising, salesforce, sales promotion, distribution and price are significantly different from zero for the brand on one-tailed tests.

The results of logistic regression analysis are presented in Table 5. The estimated equation is of the form:

$$
\begin{aligned}
\ln (p / 1-p)= & -26.6+2.94 Q_{1}+2.15 Q_{2} \\
& +1.88 Q_{3}+1.7 Q_{4}
\end{aligned}
$$

The interpretation of this equation is that all the independent variables have positive effects on log-odds, which is a function of overall customer satisfaction level. This indicates that the log-odds of overall customer satisfaction increase if the perceived customer satisfaction increases with respect to individual marketing efforts. Results also reveal that the estimated coefficients of all the marketing efforts are significant for this brand. The value of each estimated coefficient can be interpreted as the predicted change in the logodds (function of overall customer satisfaction level) associated with one unit change in the corresponding variable, holding all other variables constant. Furthermore, the exponential constant raised to the power of the estimated coefficient represents the factor by which the predicted odds ratio changes from one when the corresponding 
Table 5: Response of overall customer satisfaction to marketing efforts for Navratna

\begin{tabular}{|c|c|c|c|c|c|c|}
\hline \multicolumn{7}{|c|}{$\begin{array}{l}\text { The logistic regression equation: } \\
\text { In }(p / 1-p)=-26.60+2.94 Q_{1}+2.15 Q_{2}+1.88 Q_{3}+1.70 Q_{4}\end{array}$} \\
\hline Predictor & Coefficient & SE & z-value & $p$-value & $\begin{array}{l}\text { Odds ratio } \\
(p / 1-p)\end{array}$ & Rank \\
\hline Advertising & 2.94 & 1.09 & $2.70^{* *}$ & 0.0035 & 18.90 & $3.20(1)$ \\
\hline Salesforce & 2.15 & 0.75 & $2.71^{\star \star}$ & 0.0035 & 8.60 & $1.61(2)$ \\
\hline Distribution & 1.88 & 0.56 & $3.36^{* *}$ & 0.0005 & 6.50 & $1.05(3)$ \\
\hline Price & 1.70 & 0.48 & $3.44^{* *}$ & 0.0005 & 5.50 & $0.81(4)$ \\
\hline
\end{tabular}

Notes: ${ }^{* *}$ Significant at 1 per cent level (one-tailed).

$Q_{1}-$ Customer's emotional reaction towards advertising, $Q_{2}-$ Customer's emotional reaction towards product, $Q_{3}-$ Customer's emotional reaction towards distribution, $Q_{4}-$ Customer's emotional reaction towards price.

Table 6: Validation statistics of logistic regression equation for Navratna

\begin{tabular}{lllll}
\hline Brand & G (4) & $\boldsymbol{p}$-value & HL (8) & $p$-value \\
\hline Navratna & $38.9^{*}$ & $<0.000$ & 9.50 & 0.30 \\
\hline
\end{tabular}

Notes: *Significant at 0.001 per cent level (two-tailed).

Figures in parentheses indicate degrees of freedom.

variable changes by one unit, holding all other variables constant. For example, the multiplicative factor is 18.9 in the case of advertising. That is, the odds ratio will change from 1.00 to 18.9 for a unit increase in perceived customer satisfaction with respect to this effort. Moreover, results indicate that advertising has the greatest impact on overall customer satisfaction, followed by salesforce, distribution and price for the brand.

The validation statistics of the logistic regression equation are shown in Table 6 . Results show that the G-statistic value is 38.9. Since it is significant, this would lead one to conclude that at least one of the coefficients in the model is not zero. Further, the HL-statistic value is 9.5 and insignificant in this context. This indicates that there is insufficient evidence to claim that the model does not fit the sample data adequately for the brand.

To test where the estimated coefficients of overall customer satisfaction with respect to individual marketing efforts are significantly different from zero, the following hypothesis has been formulated in the context of Equation (2):

$\mathbf{H}_{2}$ : The estimated coefficient of overall customer satisfaction with respect to each marketing effort is zero.
Table 7: Marketing effort-wise CSI and ROI for Navratna

\begin{tabular}{lll}
\hline Effort & Navratna & \\
\cline { 2 - 3 } & CSI & ROI (\%) \\
\hline Advertising & 0.74 & 27.75 \\
Salesforce & 0.64 & 76.80 \\
Promotion & 0.74 & 70.30 \\
Distribution & 0.62 & 14.57 \\
Price & 0.55 & 27.50 \\
\hline
\end{tabular}

That is, in mathematical form, $\mathrm{H}_{0}: \lambda_{\mathrm{i}}=0$ against $\mathrm{H}_{\mathrm{a}}: \lambda_{\mathrm{i}}>0$.

The findings (Table 5) of the tests of the hypothesis suggest that the coefficients of individual marketing efforts such as advertising, salesforce, distribution and price are significantly different from zero for the brand on one-tailed tests.

The CSI of individual marketing efforts are presented in Table 7. Results indicate that the CSI for advertising is 0.74 for this brand. This means that customers are satisfied with the attributes of advertisement at a 74 per cent level. Furthermore, CSI is highest in the case of advertising and lowest in the case of price. Moreover, results reveal that the differences between the CSI of one effort and another are prominent in this case. This indicates that 
customers are not equally satisfied with the individual marketing efforts. It seems that the manager of this brand may not have formulated or implemented all the marketing efforts collectively.

The results of ROI in individual marketing efforts are also shown in Table 7. Results reveal that the ROI is highest in salesforce and lowest in distribution for the brand. That is, every rupee spent on each marketing effort does not yield the same amount of ROI over the study period. It means that the formulation and implementation strategies of each effort may impact its own effectiveness as well as others.

\section{CONCLUSION AND MANAGERIAL IMPLICATIONS}

It has been concluded that the impact on sales is different from one effort to another, because each of them has to be performed to accomplish some specific goals. But to fulfil an overall objective (increase in sales in this case) all the efforts have to be formulated and implemented collectively to get the maximum benefit of marketing expenditures.

In another dimension, the customers' emotional reactions toward different marketing efforts have significant positive effects on overall customer satisfaction. Moreover, the level of customer satisfaction varies from effort to effort in the marketing mix. That is, all the marketing efforts are not equally important to the customers.

The ROI helps the manager to identify which effort is earning and which is losing money for any brand. Moreover, it can be utilised to allocate limited resources to the different marketing efforts in question. In the case of this brand, the manager should invest as little as possible in distribution and advertising, and as high as possible in the salesforce and sales promotion efforts. By doing so, the manager can reallocate the marketing budget to individual efforts for the brand.

\section{LIMITATIONS}

There are some limitations in this study. A relatively small number of efforts have been considered, since data were not available. Further, this work has considered only the short-term effect of each marketing effort on sales. Moreover, the ROI has been calculated with respect to sales, not with respect to contribution margin, since costs data were not available.

\section{FURTHER RESEARCH}

It is desirable to assess the long-term effect of each marketing effort on sales in addition to the shortterm. The ROI in each effort may be calculated by the discounted-cash-flow (DCF) method.

\section{Acknowledgments}

We gratefully acknowledge the constant support of the firm in utilising internal documents and permission to survey customers.

\section{References}

1 Sheth, J. N. and Sisodia, R. S. (2002) 'Marketing productivity: Issues and analysis', Journal of Business Research, Vol. 55, No. 5, pp. 349-358.

2 Stone, R. and Duffy, M. (1993) 'Measuring the impact of advertising', Journal of Advertising Research, Vol. 33, No. 6, pp. RC9-RC12.

3 Basu, A. K. and Batra, R. (1988) 'ADSPLIT: A Multi-brand advertising budget allocation model', Journal of Advertising, Vol. 17, No. 2, pp. 44-51.

4 Bawa, K. and Shoemaker, R. W. (1987) 'The effects of a direct mail coupon on brand choice behavior', Journal of Marketing Research, Vol. 24, No. 3, pp. 370-376.

5 Jones, P. (1990) 'The double jeopardy of sales promotions', Harvard Business Review, Vol. 68, No. 5, pp. 145-152.

6 Macbeth, D. K. (1980) 'The role of purchasing in a partnering relationship', European Journal of Purchasing and Supply Management, Vol. 1, No. 1, pp. 19-25.

7 Ogbonna, E. and Wilkinson, B. (1996) 'Inter-organizational power relations in the UK grocery industry: Contradictions and developments', The International Review of Retail, Distribution and Consumer Research, Vol. 6, No. 4, pp. 395-414.

8 Cardozo, R. and Ship, S. (1987) 'New selling methods are changing industrial sales management', Business Horizons, Vol. 30, No. 5, pp. 23-38.

9 Powers, T. L. (1989) 'Should you increase sales promotion or add more salespeople?' Industrial Marketing Management, Vol. 18, No. 4, pp. 259-263.

10 Eskin, G. J. (1975) 'A case for test market experiments', Journal of Advertising Research, Vol. 15, No. 2, pp. 27-34.

11 Anderson, E. W., Fornell, C. and Rust, R. T. (1997) 'Customer satisfaction, productivity and profitability: Differences between goods and services', Marketing Science, Vol. 16, No. 2, pp. 129-145.

12 Ittner, C. D. and Larcker, D. F. (1996) 'Measuring the impact of quality initiatives on firm financial performance', in Fedor, D. P. and Ghosh, S. (ed.), 'Advances in the Management of Organizational Quality', Jai Press, Greenwich, CO.

13 Zinkhan, G. M. and Pereira, A. (1994) 'An overview of marketing strategy and planning', International Journal of Research in Marketing, Vol. 11, No. 3, pp. 185-218. 